\title{
Population Structure of Fusarium fujikuroi from California Rice and Water Grass
}

\author{
L. L. A. Carter, J. F. Leslie, and R. K. Webster
}

First and second authors: Department of Plant Pathology, Throckmorton Plant Sciences Center, Kansas State University, Manhattan 665065502; and first and third authors: Department of Plant Pathology, University of California at Davis, Davis 95616.

Current address of first author: Rogers Brand Vegetable Seeds, Syngenta Seeds, Inc., 6338 Highway 20-26, Nampa, ID 83687.

Accepted for publication 17 April 2008.

\begin{abstract}
Carter, L. L. A., Leslie, J. F., and Webster, R. K. 2008. Population structure of Fusarium fujikuroi from California rice and water grass. Phytopathology 98:992-998.

The recent observance of Fusarium fujikuroi, the causal agent of Bakanae disease of rice, in California provides a unique opportunity to assess the population diversity of an introduced pathogen in a new environment. We collected 172 isolates of this pathogen between 2000 and 2003 from California rice and two from water grass (Echinochloa spp.). Pathogenicity of $F$. fujikuroi was demonstrated on early water grass $(E$. oryzoides) and barnyard grass (E. crus-galli) indicating that weed control should be part of Bakanae management programs. Both mating types and

six unique amplified fragment length polymorphism haplotypes corresponding to six identified vegetative compatibility groups were detected. The two most frequently isolated haplotypes encompassed $94 \%$ of the collected isolates, suggesting that clonal reproduction dominates. Coefficients of similarity between the unique haplotypes ranged from 0.94 to 0.98 , and indicate that there is very little genotypic variation in the $F$. fujikuroi population in California. The near fixation of the MAT-1 idiomorph (observed ratio 170 MAT-1:4 MAT-2), is consistent with a hypothesis of predominant or exclusive asexual reproduction. The low level of introduced genotypic diversity, in conjunction with the asexual reproductive strategy of this population will slow evolutionary processes, including adaptation to the California environment.
\end{abstract}

Fusarium fujikuroi Nirenberg, (teleomorph: Gibberella fujikuroi Sawada) is a haploid, heterothallic ascomycete fungus, and is the causal agent of Bakanae disease of rice. Though one of the oldest known diseases of rice (15), Bakanae was not observed in California until 1999 (1). Bakanae is a monocyclic disease and the pathogen is dispersed predominantly with infected or infested seed $(10,28,35)$, although infected crop residue from the previous season also may serve as a source of inoculum $(3,38,39,44)$.

Bakanae is traditionally associated with rice, Oryza sativa, but water grass plants, Echinochloa spp., with classic symptoms of Bakanae also were observed in California in 2002 (1). Koch's postulates for the pathogenicity of $F$. fujikuroi on water grass have not been fulfilled, and isolates recovered from water grass have not been tested for pathogenicity on rice. Several species of Echinochloa, including E. phyllopogon, E. oryzoides, and E. crusgalli, are serious weed problems in California rice fields. Failure to control these weedy grasses, which has become increasingly difficult as herbicide resistance develops in the population, may reduce yield by $50 \%$ or more (11). Thus, weed control is critical for maintenance of yield, but the role of weed control in the management of Bakanae is unknown.

The teleomorph, G. fujikuroi, has been reported on rice in the field in China, Japan, and Taiwan $(38,41,43,47)$, and ascospores are reported as the primary source of inoculum for Bakanae in Taiwan (38). The teleomorph of this fungus may have been observed in California (1), but the amount of genetic and genotypic diversity present in the California population, and the extent to which sexual reproduction may influence the California population structure has not been established.

Corresponding author: L. L. A. Carter; E-mail address: laurel.carter@ syngenta.com

doi:10.1094/PHYTO-98-9-0992

(c) 2008 The American Phytopathological Society
Understanding the genetic structure of pathogen populations provides insights into their biology and evolution, and may facilitate improved disease management $(26,30,32)$. One means of examining population structure is vegetative compatibility, which divides conspecific fungi into groups based on their ability to form stable heterokaryons. Such heterokaryons form only when two isolates are identical at all of the vic loci that govern vegetative compatibility $(12,23)$. The assignment of isolates to vegetative compatibility groups (VCGs) has been used widely to characterize fungal populations, particularly for species in the genus Fusarium (4,13,23,24,26,33,34). A low level of VCG diversity is an indicator of asexual (clonal) reproduction, whereas greater VCG diversity suggests that sexual recombination may be important in the life cycle of the fungus since the multilocus vic genotypes may be reshuffled by meiotic recombination and segregation $(12,23)$. In India and China indigenous populations of $F$. fujikuroi isolated from rice $(40,46,47)$ all had high levels of VCG diversity, suggesting that sexual recombination occurs with regularity in these field populations.

Molecular markers are another powerful method for elucidating population structure. Amplified fragment length polymorphisms (AFLPs) are a reproducible method of detecting genetic variation in a population $(17,27,42)$ and, like VCG analysis, have been used to examine the diversity present in populations of Fusarium species $(18,19,45)$.

The genera Gibberella and Fusarium encompass a broad range of reproductive strategies including both homothallic (e.g., Gibberella zeae) and heterothallic (e.g., Gibberella fujikuroi) sexual reproduction, as well as solely asexual (e.g., Fusarium oxysporum) reproduction. In other members of the Liseola section of Fusarium, (e.g., Gibberella moniliformis), both clonal and sexual reproduction are important parts of the lifecycle (25), and from a plant pathology perspective, both conidia and ascospores are important in the disease cycles of these fungi. 
The relatively recent introduction of $F$. fujikuroi into California provides a unique opportunity to examine the population genetic structure of an introduced fungal pathogen. Collections of the pathogen made immediately following its first report in the state can circumscribe the amount and arrangement of genetic diversity that was imported when the introduction was made. A large number of genotypes may have been introduced when $F$. fujikuroi was brought to California, but we hypothesize that the genetic and genotypic diversity introduced was low with only a few unique genotypes persisting to create an effective population bottleneck. Tracking the population in the field in the years immediately following the introduction is needed to understand the reproductive strategy implemented by $F$. fujikuroi in California rice fields.

Though first observed in California in 1999, F. fujikuroi was rapidly dispersed and could be observed throughout most of the state's rice growing regions by 2002. Knowledge of the genetic and genotypic diversity that $F$. fujikuroi possesses in the California population facilitates educated decision making in respect to choosing control strategies. A sexually recombining population with high levels of genetic diversity is better equipped to adapt rapidly to its environment, for instance, and is more likely to rapidly develop multigenic resistances to fungicides than would a predominantly asexual population with low initial diversity. Additionally, determining the possible role of water grass species in the Bakanae disease cycle could provide further insight into the control of this pathogen, and possibly identify differences in fitness of the pathogen on alternate hosts.

The objectives of this study were (i) to characterize VCG diversity in the California population of $F$. fujikuroi, (ii) to evaluate the genetic variability as assessed by AFLP analysis, and (iii) to determine pathogenicity of $F$. fujikuroi on water grass species. Our working hypothesis was that genotypic diversity as measured by the number of both AFLP and VCG phenotypes in this population would be low. We further hypothesize that $F$. fujikuroi is pathogenic on water grass species, which has not been previously reported, and that the isolates of $F$. fujikuroi that infect water grass belong to the same population as do those that infect rice.

\section{MATERIALS AND METHODS}

Collection of isolates. Isolates of $F$. fujikuroi were collected from rice (Oryza sativa) for 4 years (2000 through 2003). Each year, collections were made throughout the rice growing season. Seedlings with early symptoms of Bakanae, particularly chlorosis and elongation, were collected from fields throughout California's rice growing regions $\approx 30$ days after planting. Later in the season, plants with visible signs of Bakanae, including mycelium growing from nodes just above the water level were collected. In this manner, roughly five infected seedlings were collected from each of 20 fields each year. In 2002, water grass (Echinochloa spp.) plants exhibiting symptoms of Bakanae were observed and collected from the field. Additionally, more samples $(\approx 50)$ were collected from each of two different fields with a high incidence of Bakanae, one in 2002 in Butte county and the other in 2003 in Colusa county.

Putative isolates of $F$. fujikuroi were obtained from symptomatic seedlings by excising roots, just below the crown, and surface sterilizing the seedling by a brief $\operatorname{dip}(\approx 2 \mathrm{~s})$ in a $1 \%$ Tween 20 solution, followed immediately by $10 \mathrm{~s}$ in $70 \%$ ethanol, and $1 \mathrm{~min}$ in a $20 \%$ bleach solution (final concentration $1.2 \%$ $\mathrm{NaOCl})$. Six cross sections were taken from the stem, starting at the crown and working upward, and placed on a single plate of modified Nash-Snyder medium (NSM) (26) in which the pentachloronitrobenzene (PCNB) was reduced to $200 \mathrm{mg} / \mathrm{liter}$, the streptomycin was reduced to $300 \mathrm{mg} / \mathrm{liter}$, and the neomycin was omitted. Explants were observed for up to 7 days for growth of the pathogen. For each infected seedling, fungal growth was transferred to Difco potato dextrose agar (PDA) (Detroit, MI).
Microconidia from the colonies on PDA were collected with a sterile inoculating loop, and streaked onto $2 \%$ water agar (Difco). Single microconidia were identified under a dissecting microscope, transferred to a fresh water agar plate, and allowed to germinate. When the resulting colonies were $2 \mathrm{~cm}$ in diameter, a $1 \mathrm{~mm}$ agar block was cut from the margin of the colony and transferred to a sterile filter paper (Fisherbrand, Grade P4, Cellulose Fiber, 4.25-cm diameter) on PDA. After the filter paper was fully colonized $\left(\approx 5\right.$ days at $22^{\circ} \mathrm{C}$ ), it was removed from the PDA and placed in a sterile petri dish and dried in a laminar flow hood until moisture had evaporated $\approx 4$ days. Dried filter paper was cut into small, $\approx 5 \mathrm{~mm}^{2}$ pieces, placed into a vial, and stored at $4^{\circ} \mathrm{C}$.

Infected plants that reached maturity had sporodochia on their stems. Isolates were collected from these plants by transferring spores from sporodochia to NSM with a sterile toothpick. Microconidia from the resulting colonies were streaked on water agar, and single spore isolates were collected and stored as described previously.

Pathogenicity testing. All isolates collected were screened for their ability to induce symptoms of Bakanae on rice seedlings. Isolates that did not cause Bakanae symptoms on rice seedlings were excluded from the remainder of the analysis. Colonies were started from a single colonized piece of filter paper placed on water agar. Isolates grew on the water agar for 2 to 3 days, until the mycelia had clearly emerged. A small $\left(\approx 2 \mathrm{~mm}^{3}\right)$ agar block was cut from the margin of the colony and transferred to PDA, where it grew until it fully covered the plate, $\approx 14$ days. Plates were flooded with sterile distilled $\mathrm{H}_{2} \mathrm{O}$ and scraped with a sterile glass slide. The resulting suspension was filtered through two layers of sterile cheesecloth and adjusted to a concentration of $10^{6}$ spores $/ \mathrm{ml}$. Twenty seeds of cultivar M-202 rice, from the California Rice Experiment Station, (Biggs, CA) were soaked in $10 \mathrm{ml}$ of spore suspension in $15 \mathrm{ml}$ centrifuge tubes for $18 \mathrm{~h}$ at $20^{\circ} \mathrm{C}$. Control seeds were soaked in sterile distilled $\mathrm{H}_{2} \mathrm{O}$ only. Soaked seeds were surface sown into 500-ml plastic cups, one tube per cup. Each cup contained autoclaved Yolo Loam soil, and was flooded so that the water level was at the soil surface. Seed cups were kept on shelves in the laboratory at $20^{\circ} \mathrm{C}\left( \pm 5^{\circ} \mathrm{C}\right)$ $\approx 32 \mathrm{~cm}$ below two 34-watt cool-white fluorescent lights with a $12 \mathrm{~h}$ photoperiod. Seven days after seeds were sown; cups were flooded to a depth of $2 \mathrm{~cm}$ above the soil level. Seedlings were evaluated for symptoms of Bakanae 30 days after sowing.

Demonstrating Koch's postulates on water grass. Two isolates of F. fujikuroi from water grass, WG3 and WG5, and two isolates from rice, Ff127-5 and Ff143-4, were tested for pathogenicity on early water grass (E. oryzoides), late water grass $(E$. phyllopogon), barnyard grass (E. crus-galli) (University of California at Davis, Plant Sciences Department), and rice cultivar M202. Pathogenicity tests were carried out in cups as described previously. At 30 days, symptomatic seedlings were surface sterilized and plated on NSM as described. Explants were scored for growth of the pathogen after 7 days.

VCG analysis. Complementary nitrate-nonutilizing (nit) mutants were generated and paired from 174 isolates of F. fujikuroi. nit mutants were generated and characterized as previously described (26). Briefly, isolates were cultured on chlorate medium $\left(\mathrm{PDA}+4 \% \mathrm{KClO}_{3}\right)$. Fast-growing sectors on chlorate medium were transferred to Difco Czapek's solution agar (CZA), which contains $\mathrm{KNO}_{3}$ as the sole $\mathrm{N}$ source. Colonies that produced wildtype aerial mycelium on CZA were discarded; colonies exhibiting flat growth were considered nit mutants. Phenotypes of nit mutants were determined by transferring the colonies to hypoxanthine medium $(\mathrm{CZA}+0.16 \mathrm{~g} /$ liter hypoxanthine). nitl mutants produced flat growth on hypoxanthine medium, while NitM mutants had wild-type growth on this medium. This process does not distinguish nitl from nit3 mutants, which were both included in a single class termed nitl in this study. 
After nitl and NitM mutants were available for 50 isolates, all possible nitl by NitM pairwise combinations were evaluated in a diallel pairing. Pairings were made by inoculating a nitl and a NitM isolate on a single CZA plate $\approx 1.5 \mathrm{~cm}$ apart from each other. Plates were incubated for 21 days and monitored for wildtype growth along the interface between the two colonies. Wildtype growth indicated that anastomosis and complementation had occurred, and that the paired isolates were in the same VCG. From the diallel pairing, six isolates were selected as testers, representing a nit 1 and NitM from three different VCGs (A, B, and C).

nit mutants from the remaining 124 isolates were co-inoculated in a three-way pairing $\approx 1.5 \mathrm{~cm}$ apart from both the nit 1 and NitM tester from a single VCG on CZA. Wild-type growth observed between tester strains derived from the same parent isolate served as a positive control. nit mutants not pairing with any of the three tester pairs were phenotyped as described previously and complementary nit mutants were generated from the same parental isolate. Complementary nit mutants from the same parent isolate were paired to verify heterokaryon self-compatibility (8) and additional tester strains (VCGs D-F) were established as necessary.

DNA extraction. Each isolate was grown on water agar for 2 to 3 days. A single agar block, $\approx 1 \mathrm{~cm}^{3}$ was cut from the margin of the colony and transferred to a 250-ml Erlenmeyer flask containing $50 \mathrm{ml}$ of sterile liquid medium $(21 \mathrm{~g}$ of D-glucose, $1.2 \mathrm{~g}$ of DL-asparagine, $1.2 \mathrm{~g}$ of $\mathrm{K}_{2} \mathrm{HPO}_{4} \cdot 3 \mathrm{H}_{2} \mathrm{O}, 0.5 \mathrm{~g}$ of $\mathrm{MgSO}_{4} \cdot 7 \mathrm{H}_{2} \mathrm{O}$, $0.1 \mathrm{~g}$ of $\mathrm{NaCl}$, and $0.5 \mathrm{~g}$ of yeast extract per liter). Cultures were incubated for 7 days at $\approx 20^{\circ} \mathrm{C}$, on a rotary shaker $(100 \mathrm{rpm})$. Mycelia were recovered by vacuum filtration through miracloth, (Calbiochem, Carlsbad, CA), lyophilized, and stored at $-20^{\circ} \mathrm{C}$. Total genomic DNA was extracted from the lyophilized mycelium as previously described (22).

Mating type analysis. A modified multiplex polymerase chain reaction (PCR) (37) was used to determine the mating type of each isolate. The annealing temperature in the amplification reaction was lowered from to 67 to $56^{\circ} \mathrm{C}$, and the modified amplification program was 35 cycles of $92^{\circ} \mathrm{C}$ for $30 \mathrm{~s}, 56^{\circ} \mathrm{C}$ for $30 \mathrm{~s}$, and $72^{\circ} \mathrm{C}$ for $45 \mathrm{~s}$, followed by a final elongation for $5 \mathrm{~min}$ at $72^{\circ} \mathrm{C}$ before cooling to $4^{\circ} \mathrm{C}$. For each PCR reaction, isolates of known mating type (BC1 and Dst1) were included as positive controls; a negative control consisting of all the PCR components except the template DNA also was included in each run. DNA fragments were separated by gel electrophoresis in a Gel XL system (Labnet International, Edison, NJ), for $25 \mathrm{~min}$ on a $1.5 \%$ agarose gel. Gels were stained for $10 \mathrm{~min}$ in an ethidium bromide solution, and bands identified under UV light. Fragment lengths were determined by comparison to a $1-\mathrm{kb}$ standard ladder (Promega, Madison, WI). Expected fragment length was 200 bp for $M A T-1$ isolates, and 800 bp for MAT-2 isolates (37).

AFLP analysis. The restriction-ligation portion of the AFLP fingerprinting was carried out as previously (42), with the following modifications. To begin, $250 \mathrm{ng}$ of DNA was digested in a 20- $\mu$ l volume containing 2.5 units $M s e$ I, 2.5 units of EcoRI, BSA, and the buffers supplied by the manufacturer (New England Biolabs, Ipswich, MA). The restriction digestion was incubated for $3 \mathrm{~h}$ at $37^{\circ} \mathrm{C}$. Five microliters of the ligation mix $(5 \mu \mathrm{M} \mathrm{EcoRI}$ adapter, $50 \mu \mathrm{M}$ MseI adapter, 1 unit T4 DNA ligase HC, and 1× ligase buffer [Invitrogen Corporation, Carlsbad, CA]) were added to the restriction reaction product, and incubated for $3 \mathrm{~h}$ at $20^{\circ} \mathrm{C}$. The resulting product was diluted 1:10 in low EDTA TE Buffer (10 mM Tris-HCl, 0.1 mM EDTA, $\mathrm{pH}$ 8).

The pre-amplification and selective amplification steps were carried out by using an AFLP Analysis System II kit (Invitrogen), according to the manufacturer's protocol with the following exceptions. Pre-amplified DNA was diluted 1:10 in TE buffer. The fluorescent dye ChromaTide tetramethylrhodamine-6-dUTP (TMR, Molecular Probes, Eugene, OR) was used to enable fragment detection with an ABI 377 DNA sequencer (Applied Biosystems, Foster City, CA). Diluted ligated DNA was subjected to a nonselective pre-amplification with a GeneAmp PCR System 9700 thermocycler (Applied Biosystems). All PCR products were stored at $4^{\circ} \mathrm{C}$.

The 64 primers included in the Invitrogen kit were tested with isolates representing both mating types and all of the VCGs found in California as a preliminary screen of the variation present. Then, eight primer pairs (EAA/MCAC, EAC/MCTC, EAC/ MCTG, EAG/MCAG, EAG/MCTG, ETC/MCAC, ETC/MCTC, and ETT/MCTT) were used to analyze all 174 strains. BC1 was included as a positive control with every primer combination and was included in every set of reactions. A water blank, containing all of the reagents in the PCR reaction except template DNA, also was included in every run as a negative control. The AFLP fragments were visualized as previously described (2). The data obtained from this analysis were indicative of the population structure, i.e., primarily clonal, but were not always reproducible.

To confirm the tentative AFLP results, a subset of 30 isolates was selected that represented all of the observed diversity, and AFLPs were run as described by Leslie and Summerell (26). AFLP primers were chosen that had two selective nucleotides on each primer, and yielded fingerprints with more bands per isolate. The following primer combinations were used, EAA/MAT, EAA/ MCA, EAA/MTT, EAC/MCA, EAG/MCT, EAG/MCT, EAG/ MTT, ECC/MCG, EGG/MCT, ETC/MCA, ETC/MCT, ETT/ MAC, and ETT/MCT. The KSU1993 (FGSC No. 8931) was included as an $F$. fujikuroi standard.

Data analysis. All isolates were scored based on VCG (A to F), and mating type, either MAT-1 or MAT-2. A binary code also was used to indicate the presence or absence of polymorphic AFLP fragments from 200 to 500 bp from the second AFLP analysis, and a rectangular data matrix of AFLP bands by isolates was constructed. Approximately $70 \%$ of the isolates tested in this manner shared $100 \%$ of their AFLP bands, an indication of the reproducibility of the results. The Arlequin software package (36) was used to identify shared composite haplotypes. The data set was clone-corrected by removing all but a single copy of each composite haplotype. Genetic distance was calculated with the IML procedure in SAS (version 9.1 for Windows) (SAS Institute, Cary, NC). Isolates with $>98 \%$ similarity were considered to be clones.

\section{RESULTS}

Pathogenicity of isolates of $F$. fujikuroi on water grass. Isolates initially collected from both rice and water grass were tested, and produced disease on rice, early water grass (E. oryzoides), and barnyard grass (E. crus-galli) (Fig. 1). Germination of late water grass (E. phyllopogon) seed was sporadic $(<10 \%)$, but no Bakanae symptoms were observed on the seedlings that did emerge. All isolates of the pathogen were successfully re-isolated from all diseased hosts. Koch's postulates were successfully completed, indicating that $F$. fujikuroi is a pathogen of barnyard and early water grasses.

VCG, mating type, and AFLP analyses. Six distinct VCGs (A to $\mathrm{F}$ ) were identified among the 174 isolates of $F$. fujikuroi isolated from rice and water grass in California. No heterokaryon self-incompatible isolates were observed in this population. VCG B dominated, with 131 isolates including the isolates collected from water grass; 31 isolates were associated with VCG A, while VCGs C, D, E, and F each contained fewer than six isolates.

One hundred seventy isolates were MAT-1 and the remaining four isolates were MAT-2. All members of the same VCG had the same mating type idiomorph with those in VCGs $\mathrm{C}$ and $\mathrm{F}$ carrying MAT-2, and those in VCGs A, B, D, and E carrying MAT-1.

Based on the AFLPs there is very little genetic or genotypic diversity amongst the isolates of $F$. fujikuroi collected from California (Fig. 2). Of the 287 AFLP bands scored between 200 and $500 \mathrm{bp}, 29$ were polymorphic among the 174 California iso- 
lates examined. An additional eight polymorphic bands are added if the KSU isolate (originally from Taiwan) is included. Based on AFLP haplotype, VCG, and mating type, there are six unique haplotypes, each corresponding to a unique VCG (Table 1). Considering only the AFLP haplotypes, the coefficients of similarity for the California isolates ranged from 0.94 between $\mathrm{CC} 1$ and Dst1, to 0.98 between Ff22-2 and BC1. Comparing the California isolates to the known F. fujikuroi isolate (KSU1993) yielded coefficients of similarity ranging from 0.92 to 0.94 between KSU1993 and CC1 and Br25, respectively.

The two intensively sampled fields showed slight differences. All isolates collected from the first field (2002) were MAT-1 and

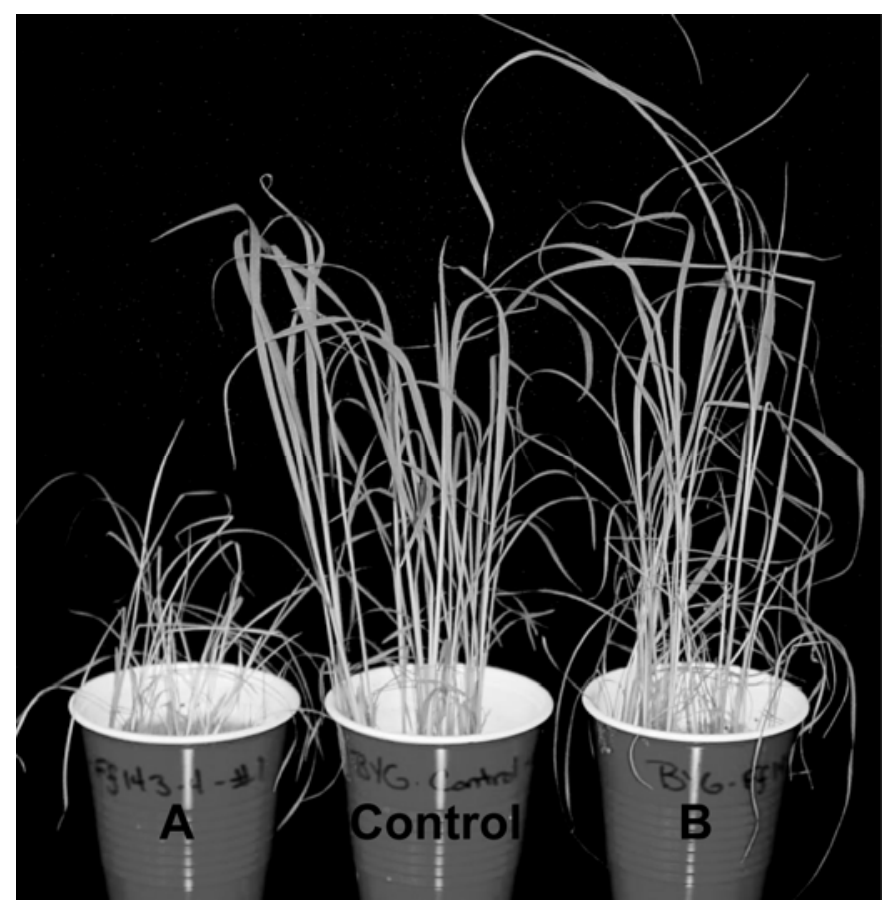

Fig. 1. Barnyard grass (Echinochloa crus-galli) exhibiting both A, stunting and $\mathbf{B}$, elongation relative to the control (center) as a result of infection by Fusarium fujikuroi. had either a $\mathrm{BC} 1(91 \%)$ or $\mathrm{CC} 1(9 \%)$ haplotype. All six haplotypes were isolated from the second field (2003), most of the isolates $(72 \%)$ were $\mathrm{BC} 1$, two of the haplotypes $(\mathrm{Br} 25$ and $\mathrm{Br} 52)$ were detected only in this field, and two of the four MAT-2 isolates detected also were isolated from this field.

The $\mathrm{BC} 1$ and $\mathrm{CC} 1$ haplotypes also were the primary haplotypes collected from the arbitrarily sampled fields, and were observed every year that collections were made. The MAT-2 isolate, Dst 1 was collected in the initial collection made in 2000 , but then was not observed again until 2002. Ff22-2 was the only other clone recovered from multiple locations, but only at very low frequency (Table 1).

\section{DISCUSSION}

F. fujikuroi is a well known rice pathogen whose epidemiology and dispersal in the California agroecosystem is not well understood. Infested or infected rice seed is the primary source of inoculum for Bakanae disease $(1,5,10,20,28,35,44)$, and disease control strategies that focus on clean seed are important for effective disease management. While important, seed is not the only possible source of inoculum. There are several reported examples of inoculum surviving between seasons in the soil and in infected crop residue $(3,29,38,39,44)$. The demonstration that early water grass and barnyard grass, both common weedy species in California rice fields, are hosts for this pathogen means that these weeds may serve as reservoirs for the persistence and increase of inoculum in a field. The isolates collected from water grass were all clones of $\mathrm{BC} 1$, indicating that water grass is already a part of the Bakanae disease cycle of California. Infected weed residue, much like infected rice residue from the previous season, could act as a source of inoculum for the following year's rice crop. Conidia present on weed stems also could infest rice seed during harvest, providing another avenue for infection, though this infection route would be a consideration only in seed production fields.

The range of potential alternate hosts evaluated was limited by the availability of seed of the weed species for laboratory study. Other possible alternate hosts for F. fujikuroi occurring as common weeds in California rice fields may include late water grass, E. phyllopogon, since the test of Koch's postulates that we conducted was inconclusive. Additionally, several other species of

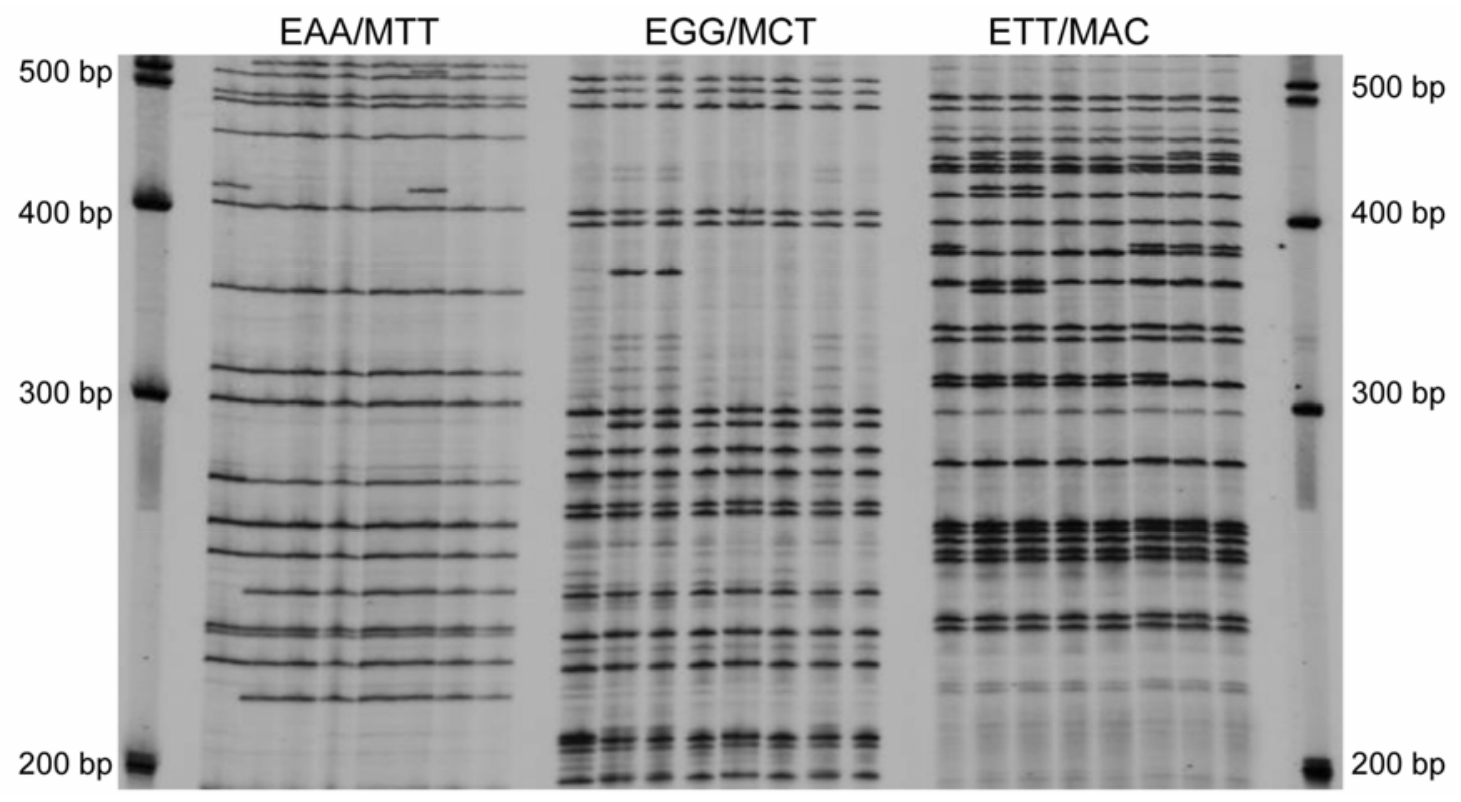

Fig. 2. Autoradiograph of an amplified fragment length polymorphism (AFLP) gel showing eight of the isolates collected from California with three different selective AFLP primer combinations (EAA/MTT, EGG/MCT, and ETT/MAC). Fragments between the sizes of 200 and 500 base pairs were scored for this analysis. This gel demonstrates the low level of variability observed in Fusarium fujikuroi isolates from California. 
economically important monocotyledonous weeds, including grasses (Leptochloa spp.), rushes (Scirpus spp.), and cattails (Typha spp.) should be evaluated. Thus, effective weed management which is already a critical consideration in California rice production to preserve yield, also may be necessary in conjunction with seed sanitation to reduce the amount of $F$. fujikuroi inoculum present in a rice field at the time of seeding, and may be considered an important component of a Bakanae disease management program.

In fungi that propagate predominantly by asexual means, isolates associated with the same VCG often are clonally related $(7,21,23,31,33)$. Our data are consistent with the hypothesis that $F$. fujikuroi in California rice fields is reproducing primarily asexually. The 174 isolates could be divided into six VCGs, and all members of each VCG shared a unique AFLP haplotype. The small number of VCGs identified in California differs from reports from other parts of the world, where F. fujikuroi populations are more diverse. In India, for example Sunder found ten unique VCGs from 28 isolates of $F$. fujikuroi (40), and in China, Zhang observed 20 VCGs from 35 isolates $(46,47)$. These results from India and China are consistent with the hypothesis that sexual recombination is occurring under field conditions, and that meiosis reassorts the vic alleles to generate many unique VCGs. The low level of VCG diversity observed in California is consistent with the hypothesis that $F$. fujikuroi was recently introduced into California, as a small number of genotypes. One scenario is that the California population was founded by a few closely related individuals, with little genetic diversity at the vic loci such that only a few VCGs (three segregating loci with two alleles per locus could produce eight VCGs) were possible even when recombination is occurring. This scenario is inconsistent with the ratios we observed for the MAT idiomorphs (170 MAT-1:4 MAT-2) in this population. In a population in which sexual recombination is occurring, the ratio should be much closer to $1: 1$ and the strains carrying the MAT-2 idiomorph should be more widely dispersed. Instead, the distribution of VCG diversity is similar to that observed in a number of asexual populations of $F$. oxysporum, in which one or a few VCGs dominate $(9,14,16)$ and other VCGs are rare if present at all. In sexual populations, VCGs are both more numerous, and present in similar numbers in the population (23).

The strains evaluated in this study included those with both mating types, and putative perithecia of $G$. fujikuroi were observed in California (1), but when the perithecia were collected the ascospores they contained were no longer viable, which precluded identification with genetic and molecular techniques. The teleomorph has been found under field conditions in Taiwan, Japan, and China $(38,41,43,47)$, and in Taiwan ascospores are reported to be the single most important source of inoculum for the subsequent year's rice crop (38). In California however, 75\% of the isolates examined, including those collected from water grass (131 of 174) belong to a single clone, $\mathrm{BC} 1$, and the two most common clones (BC1 and CC1) collectively accounted for $94 \%$ of the population (Table 1). The dominance of these two clones and the production of large numbers of asexual conidia in the field (1) both strongly support the hypothesis that clonal reproduction dominates in the Bakanae disease cycle in California. The dominance of single clones from both of the intensively sampled fields (91\% in 2002 and $72 \%$ in 2003 were clones of $\mathrm{BC} 1)$ further strengthens the hypothesis that clonal reproduction dominates in California. The slight difference in diversity observed between these fields could be due to differences in inoculum in their respective seed sources. Seed production in California is very localized, and differences in the populations of $F$. fujikuroi collected from different seed producers would not be unexpected. Although recombination could occur in the field, since both mating types are present, the AFLP haplotypes do not suggest that any of the observed haplotypes are obvious recombinants of other California types. Recombination also could be occurring at a low frequency, and the sample size may have been too small to detect the rare recombinant genotypes.

The dominance of clonal reproduction in this $F$. fujikuroi population is different from the usual reproductive behavior observed not only in this species, but also from other members of the Liseola group of the genus Fusarium. For example, Gibberella moniliformis, the pathogen of maize, regularly undergoes sexual reproduction, although clonal reproduction also may occur (25), and the resulting VCG diversity is much higher, with only a few strains belonging to each VCG (6). The high coefficients of similarity (0.94 to 0.98) among the collected isolates are consistent with the introduction of limited genotypic diversity into California, and with the collected isolates being genetically very closely related. In other populations, isolates of Fusarium often are considered to belong to the same species if they share 60 to $70 \%$ or more of AFLP bands (26). In sexually reproducing populations where the initial genetic and genotypic diversity is high, the coefficients of similarity are expected to be lower than those we observed. Even if the initial genetic diversity was low, there should be evidence of more genotypes than those observed given that 29 unlinked polymorphic bands could segregate into $>8.8 \times$ $10^{30}$ detectable genotypes.

A central question then is why does clonal reproduction predominate in the California population of $F$. fujikuroi? One possibility is that when the inoculum of $F$. fujikuroi was imported into California the ratio of MAT-1 to MAT-2 isolates was skewed, and that clonal reproduction is the only option in most cases because there is no MAT-2 isolate. Alternatively the $\mathrm{BC} 1$ clone, which is the most common in California, may have a selective advantage that makes it more fit than either the potential recombinants or its competitors. Such a situation could be stable until new genotypes were introduced into the pathogen population via mutation or migration. This scenario presumes strong selective differences between $\mathrm{BC} 1$ and the other genotypes in the population, since selection would probably require several years to make significant changes in clone frequencies, and $\mathrm{BC} 1$ has been the dominant clone of $F$. fujikuroi in California since its initial observation in 1999. BC1 also was the clone isolated from water

TABLE 1. Clones of Fusarium fujikuroi from rice fields in California

\begin{tabular}{|c|c|c|c|c|c|}
\hline Isolate & $N^{\mathrm{a}}$ & MAT $^{\mathrm{b}}$ & $\mathrm{VCG}^{\mathrm{c}}$ & County $^{\mathrm{d}}$ & Year $^{\mathrm{e}}$ \\
\hline BC1 & 131 & 1 & $\mathrm{~B}$ & Butte, Colusa, Glenn, San Joaquin, Sutter, Yolo, Yuba & $2000,2001,2002,2003$ \\
\hline Ff $22-2$ & 6 & 1 & $\mathrm{D}$ & Butte, Colusa & $2001,2002,2003$ \\
\hline $\operatorname{Br} 25$ & 2 & 1 & $\mathrm{E}$ & Colusa & 2003 \\
\hline $\mathrm{CC} 1$ & 31 & 1 & A & Butte, Colusa, Glenn, Placer, Sutter & $2000,2001,2002,2003$ \\
\hline Dst1 & 3 & 2 & $\mathrm{C}$ & Colusa & $2000,2002,2003$ \\
\hline Br52 & 1 & 2 & $\mathrm{~F}$ & Colusa & 2003 \\
\hline
\end{tabular}

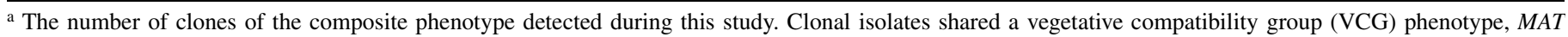
genotype, and were identical at 287 amplified fragment length polymorphism loci.

b Mating type as determined by a MAT-1 (1), MAT-2 (2) multiplex polymerase chain reaction.

c VCG, as determined by pairing of complementary nitrate nonutilizing (nit) mutants.

${ }^{\mathrm{d}}$ Counties where clones of this isolate were detected.

e Years that clones of this isolate were detected. 
grass, suggesting some modicum of fitness on other hosts as well. Thus, we currently favor the hypothesis that $\mathrm{BC} 1$ was the clone most highly represented in the population following the bottleneck event associated with this introduction, and that BC1's competitive fitness is strong enough to keep it from being readily displaced from this niche.

The recent introduction of $F$. fujikuroi into California provides a unique opportunity to evaluate this pathogen in a new environment. The collection of isolates we evaluated serves as a baseline, against which future comparisons of genetic diversity in this population can be made. Genetic diversity could increase by mutation, recombination, or through subsequent introductions of $F$. fujikuroi, and the source of such increased variation should be easily determined following comparisons with the isolates described previously. This population also is of fundamental interest due to its near fixation for MAT-1. In cases where a population is limited to asexual reproduction, Muller's ratchet should operate and deleterious mutations accumulated through time should eventually reduce the pathogen's overall fitness. If Muller's ratchet operated for a long enough time the pathogen population could disappear, due to the mutational load that would accumulate. However, due to the relatively slow rate at which such mutations accumulate, Muller's ratchet is unlikely to play any practical, near-term role in the incidence or dispersal of this disease.

In addition to monitoring the population structure of $F$. fujikuroi, future work should focus on other facets of the epidemiology of Bakanae disease in California. There are many economically important monocotyledonous weeds in California rice fields that need to be evaluated as potential hosts of this pathogen. In addition, the length of time that $F$. fujikuroi remains viable in soil and on infected crop or weed residue under field conditions needs to be determined before an integrated disease management program to control Bakanae can be designed. From an evolutionary standpoint the low observed genetic diversity, in conjunction with the predominantly asexual reproductive strategy of the California population of $F$. fujikuroi should slow the further adaptation of this pathogen to the California environment.

\section{ACKNOWLEDGMENTS}

This work supported in part by the California Rice Research Board and the Kansas Agricultural Experiment Station. Manuscript no. 07-208-J from the Kansas Agricultural Experiment Station, Manhattan.

\section{LITERATURE CITED}

1. Anderson, L. L. 2005. Bakanae Disease of Rice in California: Investigations of Disease Incidence, Spread, and Pathogen Population Structure. Ph.D. University of California, Davis.

2. Bhat, R. G., Colowit, P. M., Tai, T. H., Aradhya, M. K., and Browne, G. T. 2006. Genetic and pathogenic variation in Phytophthora cactorum affecting fruit and nut crops in California. Plant Dis. 90:161-169.

3. Biswas, S., and Das, S. N. 2003. Survival of Fusarium moniliforme in different sources. J. Mycopathol. Res. 41:55-58.

4. Bowden, R. L., and Leslie, J. F. 1992. Nitrate-nonutilizing mutants of Gibberella zeae (Fusarium graminearum) and their use in determining vegetative compatibility. Exp. Mycol. 16:308-315.

5. Chan, Z., Ding, K., Tan, G., Zhu, S., Chen, Q., Su, X., Ma, K., and Wang Ai, E. 2004. Epidemic regularity of rice bakanae disease. J. Anhui Agric. Univ. 31:139-142.

6. Chulze, S. N., Ramirez, M. L., Torres, A., and Leslie, J. F. 2000. Genetic variation in Fusarium section Liseola from no-till Maize in Argentina. Appl. Environ. Microbiol. 66:5312-5315.

7. Correll, J. C. 1991. The relationship between formae speciales, races, and vegetative compatibility groups in Fusarium oxysporum. Phytopathology 81:1061-1064.

8. Correll, J. C., Klittich, C. J. R., and Leslie, J. F. 1989. Heterokaryon selfincompatibility in Gibberella fujikuroi (Fusarium moniliforme). Mycol. Res. 93:21-27.

9. Correll, J., Puhalla, J., and Schneider, R. 1986. Vegetative compatibility groups among non-pathogenic root-colonizing strains of Fusarium oxysporum. Can. J. Bot. 64:2358-2361.
10. Dodan, D. S., Ram, S., and Sunder, S. 1994. Survival of Fusarium moniliforme in infected rice grains and its chemical control. Indian $\mathrm{J}$. Mycol. Plant Pathol. 24:135-138.

11. Fischer, A. J., Ateh, C. M., Bayer, D. E., and Hill, J. E. 2000. Herbicideresistant Echinochloa orryzoides and E. phyllopogon in California Oryza sativa fields. Weed Sci. 48:225-230.

12. Gordon, T. R. 2001. Nit mutants, anastomosis, and vegetative compatibilty. In: The Encyclopedia of Plant Pathology. O. C. Maloy and T. D. Murray, eds. John Wiley \& Sons, Inc., New York.

13. Gordon, T. R., and Martyn, R. D. 1997. The evolutionary biology of Fusarium oxysporum. Annu. Rev. Phytopathol. 35:111-128.

14. Gunn, L. V., and Summerell, B. A. 2002. Differentiation of Fusrarium oxysporum isolates from Phoenix canariensis (Canary Island Date Palm) by vegetative compatibility grouping and molecular analysis. Australas. Plant Path. 31:351-358.

15. Hori, S. 1898. Researches on 'bakanae' disease of the rice plant. Noji Shikenjo Seiski 12:110-119.

16. Jacobson, D. J., and Gordon, T. R. 1990. Fusarium oxysporum f. sp. melonis: A case study of diversity with a forma specialis. Phytopathology 81:1064-1067.

17. Jones, C. J., Edwards, K. J., Castaglione, S., Winfield, M. O., Sala, F., Van de Wiel, C., Bredemeijer, G., Vosman, B., Matthes, M., Daly, A., Brettschneider, R., Bettini, P., Buiatti, M., Maestri, E., Malcevschi, A., Marmiroli, N., Aert, R., Volckaert, G., Rueda, J., Linacero, R., Vasquez, A., and Karp, A. 1997. Reproducibility testing of RAPD, AFLP, and SSR markers in plants by a network of European laboratories. Mol. Breed. 3:381-390

18. Jurgenson, J. E., Bowden, R. L., Zeller, K. A., Leslie, J. F., Alexander, N. J., and Plattner, R. D. 2002. A genetic map of Gibberella zeae (Fusarium graminearum). Genetics 160:1451-1460.

19. Jurgenson, J. E., Zeller, K. A., and Leslie, J. F. 2002. Expanded genetic map of Gibberella moniliformis (Fusarium verticillioides). Appl. Environ. Microbiol. 68:1972-1979.

20. Kim, C. K. 1981. Ecological studies of bakanae disease of rice, caused by Gibberella fujikuroi. Korean Plant Prot. 20:146-150.

21. Klein, K. K., and Correll, J. C. 2001. Vegetative compatibility group diversity in Fusarium. Pages 83-96 in: Fusarium: Paul E. Nelson Memorial Symposium. The American Phytopathological Society Press, St. Paul, MN.

22. Lee, S. B., and Taylor, J. W. 1990. Isolation of DNA from fungal mycelia and single spores. Pages 282-287 in: PCR Protocols: A Guide to Methods and Applications. Academic Press, New York.

23. Leslie, J. F. 1993. Fungal vegetative compatibility. Annu. Rev. Phytopathol. 31:127-150.

24. Leslie, J. F. 1995. Gibberella fujikuroi: Available populations and variable traits. Can. J. Bot. 73:S282-S291.

25. Leslie, J. F., and Klein, K. K. 1996. Female fertility and mating type effects on effective population size and evolution in filamentous fungi. Genetics 144:557-567.

26. Leslie, J. F., and Summerell, B. A. 2006. The Fusarium Laboratory Manual. Blackwell Publishing, Ames, IA.

27. Majer, D., Mithen, R., Lewis, B. G., Vos, P., and Oliver, R. P. 1996. The use of AFLP fingerprinting for the detection of genetic variation in fungi. Mycol. Res. 100:1107-1111.

28. Manandhar, J. 1999. Fusarium moniliforme in rice seeds: Its infection, isolation, and longevity. Plant Dis. Prot. 106:598-607.

29. Mandal, D. N., and Sujata, C. 1988. Survivality of Fusarium moniliforme Sheld under different moisture regimes and soil conditions. Int. J. Trop. Plant Dis. 6:201-206.

30. Milgroom, M. G. 1996. Recombination and the multilocus structure of fungal populations. Annu. Rev. Phytopathol. 34:457-477.

31. Milgroom, M. G., and Cortesi, P. 1999. Analysis of population structure of the chestnut blight fungus based on vegetative incompatibility genotypes. P. Natl. Acad. Sci. 96:10518-10523.

32. Milgroom, M. G., and Peever, T. L. 2003. Population biology of plant pathogens: The synthesis of plant disease epidemiology and population genetics. Plant Dis. 87:608-617.

33. Puhalla, J. E. 1985. Classification of strains of Fusarium oxysporum on the basis of vegetative compatibility. Can. J. Bot. 63:179-183.

34. Puhalla, J. E., and Spieth, P. T. 1985. A comparison of heterokaryosis and vegetative incompatibility among varieties of Gibberella fujikuroi (Fusarium moniliforme). Exp. Mycol. 9:39-47.

35. Sasaki, T. 1987. Epidemiology and control of rice bakanae disease. Bull. Tohoku Natl. Agric. Exp. Stn. 74:1-47.

36. Schneider, S., Roessli, D., and Excoffier, L. 2000. Arlequin version 2.000: A software for population genetics data analysis. Genetics and Biometry Laboratory, University of Geneva, Switzerland.

37. Steenkamp, E. T., Wingfield, B. D., Coutinho, T. A., Zeller, K. A., Wingfield, M. J., Marasas, W. F. O., and Leslie, J. F. 2000. PCR-based identification of MAT-1 and MAT-2 in the Gibberella fujikuroi species 
complex. Appl. Environ. Microbiol. 66:4378-4382.

38. Sun, S.-K. 1975. The disease cycle of rice bakanae disease in Taiwan. Proc. Natl. Sci. Counc. Repub. China 8:245-255.

39. Sunder, S., and Satyavir. 1998. Survival of Fusarium moniliforme in soil, grains and stubbles of paddy. Indian Phytopathol. 51:47-50.

40. Sunder, S., and Satyavir. 1998. Vegetative compatibility, biosynthesis of GA3 and virulence of Fusarium moniliforme isolates from bakanae disease of rice. Plant Pathol. 47:767-772.

41. Sung, J. M., and Snyder, W. C. 1977. Before harvest occurrence of Gibberella perithecia of Fusarium moniliforme on infected rice stems in field. Korean J. Mycol. 5:33-37.

42. Vos, P., Hogers, R., Bleeker, M., Reijans, M., Lee, T., van de Hornes, M., Frijters, A., Pot, J., Peleman, J., Kuiper, M., and Zabeau, M. 1995. AFLP: A new technique for DNA fingerprinting. Nucleic Acids Res. 23:4407-4414.
43. Watanabe, T., and Umehara, Y. 1977. The perfect state of the causal fungus of bakanae disease of rice plants re-collected at Toyama. T. Mycol. Soc. Jpn. 18:136-142.

44. Watanabe, Y. 1974. The possibility of soil transmission in bakanae disease and the contamination of seeds with causal fungus during the hastening process of seed germination. Bull. Tokai Kinki Natl. Agric. Exp. Stn. 27:35-41.

45. Zeller, K. A., Bowden, R. L., and Leslie, J. F. 2003. Diversity of epidemic populations of Gibberella zeae from small quadrats in Kansas and North Dakota. Phytopathology 93:874-880.

46. Zhang, C., Zheng, Z., and Wang, G. 1998. Genetic diversity in Gibberella fujikuroi (Fusarium section Liseola) from rice. J. Zhejiang Agric. Univ. 24:583-586.

47. Zhang, C., Zheng, Z., and Wang, G. 1999. Genetic diversity in Gibberella fujikuroi (Fusarium section Liseola) from rice. Chin. Rice Res. Newsl. 7:6. 